\title{
A Necessidade de Orientação Urbanística
}

Beatriz Araujo Lara Barberis

Resumo

Propōe-se apontar o crescimento desordenado, a falta de harmonia dos bairros residenciais em verticalização e o processo descuidado, que tem gerado o seu desenho urbano.

Reforça-se a necessidade de que esse espaço urbano seja organizado a partir de propostas antecipadas de uso do solo, que contenham orientação urbanistica, que resulte em um desenho que gere uma melhor qualidade ambiental.

Abstract This article shows the disordered growth, the lack of harmony in the residential districts in vertical, and the careless process, that has created its urban design.

It reinforces the necessity that this urban space must be organized from the antecipate purposes of the use of the ground, that contain urbanistic orientation, that results in a design that begets a better environmental quality.
Mestrado pela FAUUSP, 1989.

Extraldo da Dissertaçáo de Mestrado "Desenho urbano como resultado de uma tecnologia contemporânea de edificaçắo: uma reflexăo a esse respeito", jun. 1989.

Orientador: Gian Carlo Gasperini. 
A área urbana do municlpio de São Paulo, como outras áreas urbanas de outras cidades que crescem desordenadamente, não apresenta ${ }^{\circ}$ m seus planos e leis preocupação com o equillbrio e a harmonia de seus espaços edificados. Essa falta de harmonia se expressa de forma mais contundente nos bairros residenciais com ediffcios de apartamentos - o tipo de habitação que se tornou predominante pelo rápido crescimento das populaçōes urbanas e que impôs operaçōes imobiliárias de amplitude totalmente novas, configurando fisicamente a fisionomia da maior parte dó ambiente em que vivemos e caracterizando pela quantidade o seu desenho urbano.

Os bairros de residências unifamlliares foram se transformando rapidamente em bairros verticalizados, num processo descuidado que gerou perda da qualidade ambiental, pelo crescimento disforme e desproporcional de seu desenho urbano.

A própria legislação cuidou de desordenar esse desenho. A Lei do Uso e Ocupação do Solo, para uso residencial em blocos agrupados verticalmente, embora limite a área de cada edificação em função do lote, não restringe as possibilidades de uso do terreno em termos de volume e altura edificados, desvalorizando a relação com a escala humana. Assim, encontramos ediffcios baixos sufocados entre outros altos, que lhes tiram a insolação e interferem na harmonia do conjunto edificado.

Os ediffcios de apartamentos foram construldos em lotes com dimensōes diferentes entre si, conseqüência do remembramento de lotes de residências horizontais. As soluçōes em cada lote surgiram, dessa forma, isoladas e independentes, sem nenhuma correlaçăo com o espaço adjacente e indiferentes à harmonia morfológica do bairro residencial, cada vez menos respeitada.

Sem a necessária ordenação da volumetria da paisagem urbana, a massa construfda perdeu clareza e o seu reconhecimento foi se tornando cada vez mais diffcil. Em resumo, um desenho pontilhado e irregular. Pontilhado pela obrigatoriedade de recuos em todas as faces do lote e irregular por ser alternado entre edificaçōes horizontais e verticais, pela dimensão variada dos terrenos remembrados e por năo haver um gabarito de altura para cada zona, o que propiciou a construção em diversas alturas.

Hoje vemos a mesma padronização de quarteirōes formando uma composição desordenada, sem harmonia entre as partes e sem equilbrio entre quadras com lotes construldos e quadras de lotes livres para praças, comércio, serviço e lazer.

O comércio e os sérviços, sem espaços determinados reservados para a sua localização, espalham-se por ruas com ediffcios residenciais, descaracterizando-as. As praças são raríssimas, bem como praticamente inexistentes as áreas livres e o verde, para esses bairros respirarem.

Desconsiderou-se, assim, a morfologia existente na área, as edificaçőes e as relaçőes humanas. Ediffcios foram construldos dos dois lados de uma rua projetada para residências unifamiliares, tornando-a desproporcional para o novo uso. Acentuou-se o tráfego pelo aumento do número de habitantes e, em muitos casos, esta mesma rua é utilizada como corredor de tráfego da regiâo. O dimensionamento inadequado da ocupação não atende à nova funçăo. $O$ aumento do ruldo, pelo tráfego excessivo de velculos, afeta a qualidade ambiental.

Em sintese, percebe-se a quadra urbana típica com casas e ediffcios isolados das divisas dos lotes, com espaços livres fragmentados, perdidos em corredores de circulação, recursos inexpressivos e muitas vezes subutilizados. Não existe o desenho da quadra como um todo e sim o "desenho" do lote e no lote o ediffcio. Um modelo único se repete no espaço urbano, e diante dele, podemos deduzir a Lei de Uso e Ocupaçáo do Solo, acabou surgindo mais como mecanismo de reação às pressð̌es mercantis da vida urbana, do que como fruto da observação atenta e minuciosa do desenho da cidade e de suas relaçőes humanas.

\section{Alertas e Propostas}

É imperioso, reforçamos, por isso, a necessidade de o espaço verticalizado ser organizado a partir de propostas que busquem o prévio dimensionamento para integração 
com o entorno edificado. Sem essa preocupação, os ediff́cios continuarão a apresentar alturas e linguagens arquitetônicas extremamente heterogêneas e individualistas em cada solução, agravando o processo de descaracterização da cidade. Ou seja, é urgente repensar propostas antecipadas de uso do solo e adequá-las da melhor maneira possivel à vida humana, visando a um desenho urbano que não repita os erros anteriores.

A qualidade dessas configurações urbanas não é discutida. Esse é o desenho urbano assimilado e aceito em nossa cidade, que continua a desfigurar-se apesar de análises e alertas feitos por arquitetos, tais como o de Anhaia Melo que, em 1946, propunha fixar limites para o crescimento da área urbana de São Paulo, alturas máximas para os ediffcios comerciais e residenciais e adotar o principio de unidade da vizinhança para os loteamentos atuais e futuros, rearticulando a vida comunitária. (Melo apud Leme, 1982, p. 61)

Oscar Niemeyer ao tratar do projeto de reurbanizaçāo da margem do Rio Tietê comenta: "Quem olha o mapa de São Paulo sente logo que esta cidade cresceu sem controle e como é correta a premissa de que uma cidade feita para um milhão de habitantes não pode ter quatorze, sem se poluir e desmerecer.

"Onde estão os espaços verdes que a vida reclama? Os parques e jardins que dão às cidades as caracterlsticas humanas indispensáveis? Onde está a tranqüilidade que São Paulo, anos atrås, exibia?" (Niemeyer, 1986, p. 5)

Gasperini (1987, p. 58), também já assinalou que estamos assistindo à revolução de "suburbização" das cidades onde prevalecem os valores transitórios, passageiros e, portanto, despersonalizados e insensiveis ao contexto.

Da estrutura tradicional do espaço urbano, formada pela rua, quadra e o lote, à estrutura formada por superffcies indivisas tipo superquadras, em geral podemos dizer que no primeiro caso falta harmonia e cuidado com o desenho urbano; no outro, pelo radicalismo das soluçōes quando repetido identicamente, ocorre uma monotonia do espaço urbano.

Porém, podemos dizer, como Hughes (1979), que estamos muito ansiosos em fazer com que nossas cidades funcionem do modo como elas são e apoiá-las da melhor maneira possivel, cuidando com equillbrio e harmonia dos vários aspectos que afetam a qualidade ambiental do espaço construído, dentre elas do seu desenho urbano, nos detendo sobre as alternativas de alteração e intervenção concretas. Ou seja, sem o radicalismo da cidade hiperplanejada.

Gostarlamos de lembrar que Josep Llufs Sert, pelos anos 50, já havia criado, na Universidade de Harvard, o Departamento de Desenho Urbano. Esse departamento tinha caráter interdisciplinar e representava um esforço de exploração da corresponsabilidade do desenho, não só como tradução do programa em formas, mas também como prova de suas limitaçōes e fonte de sugestōes simbólicas e mesmo críticas. Para isso Sert conta cada vez mais com a História e a recuperação das morfologias urbanas, em clara visão, até certo ponto, autocrfticas, de suas etapas iniciais no seio do C.I.A.M. (Congressos Internacionais de Arquitetura Moderna). Desenvolve projetos pilotos destinados à requalificação de setores, relativamente centrais, em várias cidades do Estado de Nova lorque, para a "Urban Development Corporation". estabelecendo e criando normas e precedentes para orientar futuras inversőes particulares, procurando em seus projetos de "fragmentos da cidade" inserir o ediflcio como parte de um conjunto urbano, estudando suas proporçōes de volume em relação a outros ediffcios, aos espaços abertos e às ruas contlguas. Com a consciência da cidade como matriz da arquitetura.

Em 1974, Sert presidiu o comitê encarregado de apresentar uma súmula do Código Internacional do Habitat Humano à Conferência das Naçōes Unidas sobre Assentamentos Humanos, que teve lugar em Vancouver, Canadá, em maio de 1975. Fruto desse periodo de trabalhos e troca de idéias é a formulação dos princlpios práticos que nortearam o próprio trabalho em prol de um habitat equilibrado, sugerindo: 
- equillbrio entre o particular - habitação e o comunitário - seçviços e equipamentos;

- equilibrio entre os âmbitos de pedestrés e automóveis;

- equillbrio entre construçőes e zona verde, entre o número de pessoąs e de árvores;

- equilfbrio entre recreação passiva e ativa, ou seja, entre lugares para o recolhimento e lugares de reuniōes e jogos;

- equillbrio entre os elementos naturais e elementos construldos;

- equillbrio entre tecnologia avançada e métodos tradicionais, que em muitos casos implica uma adequada combinaçăo de ediffcios altos e baixos. (Freixa, 1979, pp. 205, 208)

Como esta, muitas experiências têm sido apresentadas e sugerem novos desenhos do espaço urbano, com intençőes de melhoria da qualidade ambiental. Justifica-se, portanto, sempre e a qualquer tempo, discutir suas idéias e caminhos na formulação de um desenho urbano mais equilibrado e harmónico para as cidades modernas.

Em busca desse equillbrio no processo de transitoriedade das áreas urbanizadas, achamos necessário apontar algumas sugestőes que levem em consideração a necessidade de orientação urbanfstica, contando que estas possam vir a ser discutidas e a estas se somem outras sugestōes e propostas.

Achamos que o Plano Diretor da área urbanizada do município deva ser complementado por parâmetros para o desenho da cidade, ou seja, acrescido de orientação urbanistica que considere fatores, como: ecologia, topografia, densidade demográfica, dimensionamento das ruas, altura e volume das edificações, áreas verdes, paisagismo e áreas livres.

Os órgãos de planejamento sentem através de reivindicações da população ou de incorporadoras, as tendências de crescimento. Têm instrumentos, portanto, para atuar por antecipação e não apenas por pressão. $O$ importante é que os planos se antecipem à ocupação urbana, para não apenas confirmarem estruturas já existentes, e que sejam respeitadas as suas diretrizes, para que se mantenha uma coerência e continuidade. Ou seja, é preciso adotar soluçōes que, iniciadas em uma administração, tenham prosseguimento nas seguintes, criando o princlpio da colaboração permanente e construtiva que as diretrizes públicas exigem.

Para salvaguardar esse processo, ou melhor, o desenho urbano da cidade, propomos a criação de uma comissão, formada por exemplo, por membros do IAB, por pessoas cujos projetos e obras, e não apenas a formaçāo teórica, evidenciem a preocupação com a renovação urbana. A comissão seria um ponto de passagem obrigatório para análise de novas propostas de alteraçōes urbanas, ainda que năo tivesse o caráter de veto. Sua missão seria evitar que o zoneamento, como uma mera legislação, seja alvo de modificaçōes de critério polțico, como, lembramos, a criação das operaçōes interligadas entre a prefeitura e a iniciativa privada, que possibilita ao incorporador avançar a área construfda além do que a lei permite, em troca de recursos ao municlpio para a construção de habitações populares. (VEJA, 1989, p. 100)

São medidas como essas que refletem o descaso com que se trata do nosso espaço urbano, do ambiente e da qualidade de vida na cidade de São Paulo.

Ainda que tais recursos se destinem a uma causa nobre, que exige soluçăo urgente, há que se pensar nas conseqũências a longo prazo, na resultante descaracterizaçăo volumétrica da cidade. Poder-se-ia estipular para a cidade um teto de até 4 pavimentos, sem se cobrar esse recurso. Para áreas em que fosse apropriado maior número de pavimentos, por exemplo 12, se cobrariam tributos a partir do quinto até o décimo segundo pavimento, mas não além dos limites já estipulados pela legislaçăo.

A Regulamentação Urbanlstica năo deve se limitar aos aspectos de restrição e contenção. Deve-se abandonar a postura restritiva e passiva, adotando-se uma postura criativa e de estimulo. 
Os arquitetos, urbanistas, sociólogos, pela sua posição de técnicos e artistas diretamente ligados aos grupos capazes de aconselhar novas orientaçōes, têm um relevante papel a desempenhar na reformulação da organização espacial (tipologias que não a da configuração atual), tentando afastar o irracionalismo e procurando harmonizar o desenvolvimento da cidade.

As universidades de arquitetura e urbanismo poderiam colaborar, criando a disciplina de desenho urbano e apontar diretrizes para se chegar às propostas de maior harmonia e equilfbrio, particularmente para as áreas residenciais e em especial as áreas em verticalização.

Um primeiro passo para a consciência comunitária de espaços mais agradáveis e habitáveis pode ser a incorporação da matéria sobre arquitetura das cidades nas escolas de $1^{\circ}$ e $2^{\circ}$ graus, contribuindo, assim, para a formação de uma consciência pública a respeito da condição ambiental.

O ambiente onde se vive influi diretamente em nosso estado de espirito. A qualidade de uma habitação é determinada por muitos fatores, um complexo de funções que alcançam um determinado grau de habitabilidade. Na construção de ediffcios é fundamental, nesse sentido, a relação com seu entorno, a proporçăo entre os volumes construldos e as áreas livres para o conjunto edificado e suas conexōes com serviços, comércio e lazer. A previsão e a organização desse espaço, com oferta de múltiplos equipamentos para provisão e lazer em locais próximos, devem ter sempre como parâmetro a escala humana, se o objetivo for a criação de espaços equilibrados e harmônicos.

Nesse sentido, tentamos sugerir que uma orientação urbanfstica deva compatibilizar:

- urbanização com ecologia;

- traçado das ruas com topografia;

- hierarquia das ruas com largura das ruas;

- automóvel com pedestres;

- largura da rua com densidade demográfica, altura dos ediffcios e paisagismo;

- volumes edificados com topografia, escala humana e áreas livres;

- densidade edificada por unidade de vizinhança com áreas verdes proporcionais.

Em áreas já urbanizadas, o aumento de densidade demográfica, acima do suportável para a região, acarretará congestionamento do tråfego. Seria necessário, então, a implantação de vias expressas (dimensionadas pela carga de trânsito que devem suportar e suas funçōes), transportes públicos e de áreas descongestionadas livres e verdes. Mas, se não é possivel alterar a estrutura existente, que se insira neste contexto, somente o que é compatlvel com ele, dentro dessa estrutura, tentando compatibilizar os ponto relevantes citados.

Dentre todos os pontos mencionados, acreditamos ser básico para conter a metamorfose em curso, uma intervenção efetiva em relação à densidade demográfica. Como sugeriu Niemeyer (1980, p. 59), para a cidade do Rio de Janeiro, e que serve como exemplo para outras cidades que sofreram o mesmo tipo de desenvolvimento na área urbana: deverfamos adotar um gabarito máximo de quatro pavimentos como medida provisória para conter o crescimento demográfico em áreas já sobrecarregadas, pois, como se sabe, a circulação é a base do urbanismo. E, para o equillbrio das áreas já edificadas, a criação de praças com estacionamento no seu subsolo, em quarteirōes escolhidos para serem desapropriados.

Em linhas gerais, a busca de uma maior harmonia da paisagem urbana pode resultar da compatibilização dos pontos relevantes citados ao uso da estrutura tradicional (rua, quadra e lote), em um plano diretor para um setor, que por sucessivos desdobramentos possa chegar a nivel de quadra, gerando um desenho orientador e organizado capaz de realçar qualidades urbanas e resgatar a qualidade ambiental. 


\section{Referéncias Bibliográficas}

FREIXA, Jaume. Josep Lluis Sert. Barcelona. Gustavo Gili, 1979.

GASPERINI, Gian Carlo. Contexto e Tecnologia - O Projeto como Pesquisa Contemporánea em Arquitetura . São Paulo, 1987, Tese - Live Docéncia, FAUUSP.

HUGHES, Robert. "As cidades ideais", in: O choque do novo. Munich: BBC TV Production in Association with Time Life Films and RM Productions. 1979. (vldeo)

LEME, Cristina Silva. Planejamento em Săo Paulo: 1930-1969. Såo Paulo, 1982. Dissertaçåo Mestrado, FAUUSP.

NIEMEYER, Oscar. Rio, texto e croquis, de provincia e metrópole. Rio de Janeiro: Avenir, 1980.

- et alli. Parque do Tietê: plano de reubanizaçăo da margem do Rio Tietê. Săo Paulo: Almed, 1986.

VEJA, 1989. Escalada Social, 7 de junho, pp. 100-101. 